\title{
How do Air Traffic Controllers Use Automation and Tools Differently During High Demand Situations?
}

\author{
Joshua M. Kraut ${ }^{1}$, Joey Mercer ${ }^{2}$, Susan Morey ${ }^{3}$, Jeffrey Homola ${ }^{4}$, Ashley Gomez ${ }^{5}$ \\ San Jose State University/NASA Ames Research Center, Moffett Field, CA, 94035, USA \\ and \\ Thomas Prevôt ${ }^{6}$ \\ NASA Ames Research Center, Moffett Field, CA, 94035, USA
}

\begin{abstract}
In a human-in-the-loop simulation, two air traffic controllers managed identical airspace while burdened with higher than average workload, and while using advanced tools and automation designed to assist with scheduling aircraft on multiple arrival flows to a single meter fix. This paper compares the strategies employed by each controller, and investigates how the controllers' strategies change while managing their airspace under more normal workload conditions and a higher workload condition. Each controller engaged in different methods of maneuvering aircraft to arrive on schedule, and adapted their strategies to cope with the increased workload in different ways. Based on the conclusions three suggestions are made: that quickly providing air traffic controllers with recommendations and information to assist with maneuvering and scheduling aircraft when burdened with increased workload will improve the air traffic controller's effectiveness, that the tools should adapt to the strategy currently employed by a controller, and that training should emphasize which traffic management strategies are most effective given specific airspace demands.
\end{abstract}

\section{Nomenclature}

$\begin{array}{ll}\text { ATC } & =\text { Air Traffic Control } \\ \text { CPA } & =\text { closest point of approach } \\ \text { D-side } & =\text { Radar-associate } \\ \text { FAA } & =\text { Federal Aviation Administration } \\ \text { LOS } & =\text { loss of separation } \\ \text { MACS } & =\text { Multi Aircraft Control System } \\ \text { NAS } & =\text { National Airspace System } \\ \text { TRACON } & =\text { Terminal Radar Approach Control }\end{array}$

\section{Introduction}

$\mathrm{N}$ EXTGEN is a plan envisioned by the FAA to advance the state of the NAS. NextGen aims to create an air transport and travel environment which is safe, convenient, predictable, and environmentally friendly. ${ }^{1}$ NextGen will develop and implement new technologies, concepts of operations, and supporting infrastructures capitalizing on existing technologies, some of which have previously been implemented as a result of work in NextGen.

\footnotetext{
${ }^{1}$ Research Psychologist, Human-Systems Integration Division, NASA ARC MS 262-2, and AIAA Member.

${ }^{2}$ Senior Research Psychologist, Human-Systems Integration Division, NASA ARC MS 262-4, and AIAA Member.

${ }^{3}$ Research Engineer, Human-Systems Integration Division, NASA ARC MS 262-4, and AIAA Member.

${ }^{4}$ Senior Research Psychologist, Human-Systems Integration Division, NASA ARC MS 262-4, and non-member.

${ }^{5}$ Research Psychologist, Human-Systems Integration Division, NASA ARC MS 262-4, and non-member.

${ }^{6}$ Senior Research Engineer, Human-Systems Integration Division, NASA ARC MS 262-4, and AIAA Member.
} 
NextGen is a massive endeavor to look at every aspect affecting the safety, efficiency, predictability, and environmental factors which might impact the NAS. This includes everything from streamlining and improving individual avionics components to coordinating and predicting the movement of thousands of aircraft on a daily basis. Of course, with every change made, its effects on other parts of the system must be taken into account. Furthermore, as a vital component, humans must interact seamlessly within the system and with the system. Systems must account for, and take advantage of, strengths and weaknesses of human performance and experience, as well as differences which exist between individuals.

The general purpose of this exercise is to better understand the implication of controllers' individualized techniques and strategies for managing aircraft, while using NextGen tools and automation, under conditions of elevated demand. Before discussing the differences in strategy and implications on the implementation of tools and automation in NextGen, a discussion on why this comparison might be of interest.

With research involving human participants, it is generally understood that every person differs from the next. An individual's unique combination of cultural experiences, intelligence, stress, diligence, visual acuity, muscle reflexes, just to name a few, are going to shape his/her interaction with the system. In the context of an ATC environment, a single problem space may be resolved with more than one solution. ${ }^{2}$ For example, sector configuration, traffic characteristics, workload, etc. require strategies that minimize the likelihood of controller overload or an unsafe event. ${ }^{3,4}$ There is also literature discussing the types of clearances controllers use to manage aircraft ${ }^{5}$ as well as different tools and automation which may be used in NextGen ATC environments. ${ }^{6}$ These strategies employed by controllers might also vary as a combination of factors. That is, two controllers may use the tools identically under normal circumstances, but when workload increases, or some other factor changes, the strategies of the two controllers may deviate, or vice versa.

Regarding the differences in individualized use of automation, Ref. 7 presented evidence that strong differences were found between pilots' strategies for using autopilot in a multitask environment. Specifically, among five pilots, three completely different strategies were developed for managing the use of the autopilot systems, none of which were predicted or intended by the autopilot designers. Similarly, research has shown the use of data communications by flight crews and $\mathrm{ATCs}^{8,9}$ corresponds with an increase in visual and manual workload, and a decrease in auditory and speech workload. This research lends itself to the idea that when developing tools and automation for use by ATCs, it is important to understand how they will be used and that different strategies elicited by individual ATCs can lead to differences in performance.

One of the biggest concerns in developing tools and automation to assist controllers in their objectives is that of the high demand situation. Of course, tools and automation should improve safety, performance, workload, etc. during normal operations, but during times of elevated demand, or when demand on controllers is highest, tools and automation should improve performance and decrease workload, and at least not hinder safety. Another important implication for the research presented in this paper was addressed by Ref. 10. Their research gave evidence for the ability of ATCs to adapt, or switch strategies, as a response to different levels of mental workload in a simulated ATC environment. This indicates that, not only should designers be concerned about how tools and automation will be used, but also when they will be used. Therefore, in analyzing the results of this experiment, a goal is to determine how to conduct future research to assist in the design and development of NextGen tools and automation, or train for their use, to best assist controllers in their objectives, during high demand situations.

Perhaps, learning more about how and when controllers choose to implement different strategies can assist in determining training methods for controllers, or provide support for designing tools and automation that work effectively regardless of which strategies are being used. Another paper also makes recommendations for tool and automation development based on ATC strategies observed in the same experiment as the present paper: instead with a spotlight on 14 experimental trials, regardless of difficulty or workload. ${ }^{11}$ A third paper gives a more general overview of the experiment and provides findings from a priori conditions. ${ }^{12}$

The human-in-the-loop experiment required ATCs to manage aircraft in en route sectors which feed Atlanta TRACON with arrivals to Hartsfield-Jackson Atlanta International Airport. The ATCs were given decision support tools and automation to assist in their tasks, but gave voice commands to aircraft flying within their sector. The original concept of the experiment is to determine levels of acceptable trajectory prediction error caused by errors in forecast winds and aircraft performance when en route controllers use tools and automation associated with trajectory prediction to assist in spacing arrival aircraft to a point, also called a meter fix.

Given the ability of ATCs to adapt to the difficulty of the task environment, and their predisposition to use the same tools and automation to a different effect and degree, an attempt is made in this paper to discuss and present the data of two specific controllers, while they managed identical airspace, over the course of one trial. The trial chosen was only one of seventeen trials using the same tools and automation; albeit with different levels of error 
built into the trajectory predictions, per experimental design. Trial 16 is selected for this investigation for its high demand.

The two chosen controllers, each controlling identical sectors with identical traffic scenarios, were selected because observers noted during the course of the experiment that they often chose to use the information provided by the tools and automation differently and strategically managed aircraft in different ways. As an example from several observations, controller "Alpha" preferred to use the graphical route construction tool to work out a complete route, and then transmit the name of each waypoint to the pilot. Controller "Zulu" would on occasion, turn an aircraft toward a heading, and then turn the aircraft back after some time.

There are some expected differences when comparing the results of these two controllers during the experimental trials. The results in this report focus on objective measures of performance and efficiency, and some subjective measures of workload. These will provide insight into the ways controllers are affected during times of elevated difficulty. Expected, is some form of validation that notes made by observers are reflected by measures recorded during the simulation. That is to say, that these two controllers did in fact control aircraft and utilize the tools and suggestions made by automation in different ways, at least part of the time. Just as an example, but in line with what was observed during the experiment, Zulu may regularly command more heading changes, or Alpha might take the time to construct each route and instruct the crew to update their flight plan to cross each waypoint in the constructed flight plan. Another interesting aspect is the safety, efficiency, and performance differences for each of these controllers; comparing, for instance, the average distance travelled through their respective sectors or the average separation between aircraft within the sector.

The current work provides a first look into how individual controller strategies for managing traffic might affect safety, workload, efficiency, and performance when using NextGen-like tools and automation during high demand situations. Developing tools and automation, and training controllers to effectively deal with high demand situations helps ensure that stringent safety standards are met. In a system which is already one of the most complex in the world, and becoming ever-more complex, differences in strategies between controllers may make a large impact on the safety and efficacy of the system.

\section{Methods}

\section{A. Participants}

Twelve retired, radar-certified ATCs participated in the present simulation, and were monetarily compensated for their participation. One of the controllers is female, and all have normal or corrected to normal vision. Each experimental world consists of two experimental ATCs managing arrival and overflight aircraft travelling through their sector. A single experimental controller handles traffic in a "High" sector, which feeds descending arrivals to a single controller managing the "Low" sector. The two confederate ghost ATCs in a world manage aircraft in sectors surrounding the experimental sectors, adding realism and dynamism to the simulation environment. Lastly, the two D-side controllers in each world are tasked with recording real-time actions and judgments of automation use, made by the experimental controllers. The D-side controllers also assist the experimental controllers with making and taking aircraft handoffs to and from the surrounding sectors. Two identical worlds were implemented to double the amount of data collected during the experiment.

\section{B. Apparatus}

A simulation world is created by using MACS software to simulate ground-side and air-side operations in the NAS. ${ }^{13}$ Equipment used by the ATCs during the experiment is chosen to closely replicate the look and feel of equipment used at FAA traffic management facilities. The scenarios were modified from historical real-world traffic, wind, and route data to meet requirements of the experimental design. The two identical simulation worlds are run in parallel and are fully independent of each other. Voice communication equipment is utilized, enabling voice communications between the pseudo-pilots and ATCs.

The controllers were able to utilize tools to assist with their usual sector tasks as well as aircraft schedule conformance at the meter fix. The tools referred to in this paper refer to those tools which assist in the maneuvering of aircraft. For example, a participant in this paper is said to use tools when giving instructions for reroute requires the pilot to update the flight plan of the aircraft. The controller is able to determine this updated flight plan by dragging the graphical depiction of the aircraft's flight plan to waypoints which "snap" the flight plan into place, or by requesting the automation provide an updated route which conforms to the scheduled time of arrival. The controller is able to determine how the flight plan affects schedule conformance by a time displayed near the aircraft symbol, which depicts how early or late the aircraft will arrive at the meter fix if flying directly to that point from the current position. On the other hand, when not using tools, a controller would, instead of using the graphical 
reroute tool to issue route clearances to the aircraft, instruct the flight crew to fly off course using headings. Once the controller believes the aircraft conforms to the schedule, by seeing the schedule conformance time near the aircraft symbol, the controller would then give a final course clearance toward the meter fix.

When using and not using the tools, as defined in this paper, both controllers can "probe" the automation for recommendations regarding route, altitude, and speed. The difference is the method by which they handle the reroute. The tool using controller would be more likely to update the computer with the recommendations provided by the tools, and transmit those instructions to the aircraft; while the non-tool using controller would be more likely to not adjust the flight plan of the aircraft, issue headings until heading to the meter fix, then updating the host computer once on a direct path out of their sector.

Using the graphical reroute tool also provides conflict feedback. If altering the flight plan of an aircraft results in a conflict with another aircraft, the aircraft and point of conflict are displayed. Additionally, a conflict list is provided which displays a list of currently conflicting aircraft and time to LOS. Lastly, a number is displayed next to the callsign of an aircraft which is in conflict with another aircraft. This number depicts the time in minutes to LOS.

\section{Workload Queries}

Online workload queries were included to measure subjective workload of the experimental ATCs. These realtime queries were presented every 3 minutes during the simulation, but would "time-out" after 20-seconds with no response from the ATC. Each query was presented at the top of their MACS display, coupled with an audible "ding". Before the experiment began the ATCs were given the following instructions regarding the meaning of each of the ratings on the scale: $1=$ very low workload, very little traffic, hardly anything to do, time to talk; $2=$ low workload, light traffic, time to give best routes, time to talk; $3=$ somewhat low workload, in the groove, firm grasp of the flick, proactively looking for conflicts, still provide services; $4=$ somewhat high workload, mostly in the groove, still have the flick, proactive most of the time but focusing more on the separation management over providing services or other tasks with less priority; 5=high workload, having trouble keeping the flick, working reactively instead of proactively, relying heavily on automation tools; $6=$ very high workload, on the verge of losing the flick, reactive and scramble mode, falling behind in routing tasks, cannot take on any additional tasks.

Questionnaires were also proctored after each trial, which include questions related to workload (see Appendix). The questions ask the ATCs to rate their workload during the busiest portion of the trial on different factors. The ATCs responded on factors related to their mental activity, time pressure, frustration, and overall success with aircraft separation, on a scale from 1 - 7. With 1 being "Very Low" or "Not At All", 4 being "Moderate", and 7 being "Very High".

\section{Procedure}

All ATCs were given training prior to the experiment. They gained familiarity with their sector's traffic patterns, rules, and requirements, as well as the advanced tools and concepts that would be used during the experimental trials. Each of the trials during the experimental phase lasted approximately 55 minutes. After each trial was complete, the ATCs completed a post-trial questionnaire. After all experimental trials were complete the ATCs then completed a more exhaustive post-simulation questionnaire.

Each controller managing an experimental sector also had assistance with aircraft handoffs and sector planning from a D-side controller. Another task of the D-side controller was to log commands given by the experimental controller, and how close those commands approximated suggestions given by the automation. The general flow of aircraft was toward the Southeast, first from a confederate "Ghost" controller, to the "High" experimental sector, then the "Low" experimental sector, where the aircraft would cross the meter fix, and finally to another confederate Ghost controller. The arrival aircraft entering the High sector originated from the North and West. These aircraft, according to the discretion of the ATC, began their descent from cruise altitude within the High sector, before eventually being handed off to the Low sector. One of the primary goals for both High and Low controllers, after maintaining safe aircraft separation, is to deliver the aircraft to the meter fix to conform to the aircraft's scheduled times: within a +/- 25s buffer time period, while maintaining standard separation. A speed and altitude restriction was part of the airspace configuration for the meter fix; however, due to the adjustment of speed to meet the arrival time, speed restrictions were often lifted for the meter fix.

\section{E. Design}

A quasi-experimental repeated measures design was employed in the current study, with various wind and performance error conditions. However, this paper looks in depth at a single higher workload scenario. This scenario incorporates "realistic" aircraft performance errors, and "realistic" wind speed errors. Therefore, understanding the error types and their relationship to trajectory prediction uncertainty is not relevant for the current paper. Again, 
interested parties can look at Ref. 12 for an overview of results regarding the primary experimental conditions for all trials.

\section{Results}

While four experimental controllers participated in the simulation experiment, most analyses and data presented focus on two controllers, referred to as Alpha and Zulu. Evidence is given which shows that the chosen trial had higher demand associated with managing traffic than many of the other experimental trials. Data is also presented which demonstrates that these


Figure 1. Aircraft plot of routes. These plots show ATC Alpha on left, and ATC Zulu on right. Color is a representation of altitude, with warmer colors indicating a higher altitude.

two controllers do indeed use the tools and automation in both strategically and tactically different ways. However, the primary goal is to determine how controller strategy and tool use change in high demand situations. Fig. 1 shows the altitude, indicated by color, and trajectory plots of aircraft during trial 16, for each of the two ATCs. The managed sector consists of the larger, arrowhead shaped outline. At about where the aircraft plots change color to green is the location of the altitude in which the next ATC would gain aircraft control.

Comparing each of the plots, it is apparent that the two ATCs engaged different strategies to manage their aircraft's time to arrive at the meter fix. ATC Alpha descended the aircraft, the red to yellow color change, much further into the sector than ATC Zulu; while ATC Zulu directed the aircraft to descend almost immediately upon entering the airspace. The strategy employed by ATC Zulu allows the aircraft to fly slower without having to make such drastic route changes. This strategy is also likely more efficient, because the small turn off course, then turn back on course allows the pilots to idle the engines for longer in descent. With more turns and more level flight, more power is required to keep the aircraft flying at proper speed. Another advantage to the strategy of ATC Zulu is safety. The flight paths of aircraft from different inbound flows cross less often, thereby creating less opportunity for aircraft to come into close proximity. Following is further evidence for these claims, provided in the form of objective and subjective measures taken during the course of the experiment.

\section{A. Air Traffic Controller Action Events}

Action events were derived from actions made during the experiment by the ATCs regarding events such as, but not limited to, manipulating and executing changes made by the graphical trial planner and automation tools, assigning speed, turning off the conflict display, selecting an item within an aircraft's data tag, displaying the current trial plan, sending a point-out, and setting a temporary altitude. Events which were excluded from data were actions made by the ATCs regarding transfer of aircraft control, minimizing and moving the aircraft's datablock, and incorrectly input commands, such as typos and syntax errors. In Fig. 2, a graph depicts the number of action events taken in each trial by each ATC. There are two things gleaned from interpreting the data and subsequent graph. First, trial 16 shows a higher total number of action events $(M=583)$ compared with the average for the rest of the trials $(M=373.84)$. This provides the first step in verifying that trial 16 was indeed more difficult than many of the other experimental trials. Secondly, the data indicates that ATC Alpha $(M=431.29)$ typically executes more physical actions in the process of managing the sector's airspace, compared with Zulu $(M=341)$. This provides the first evidence towards verifying that the controllers employed different strategies while managing sector traffic. 


\section{B. Clearance Types}

Another way to verify that differences exist between the strategies of the two controllers is to compare the types of clearances they issue. "Descend via" is a command given to an aircraft which instructs the crew to descend the aircraft according to specified charts. These charts specify normal procedures for altitude, speed, and waypoint crossing restrictions.

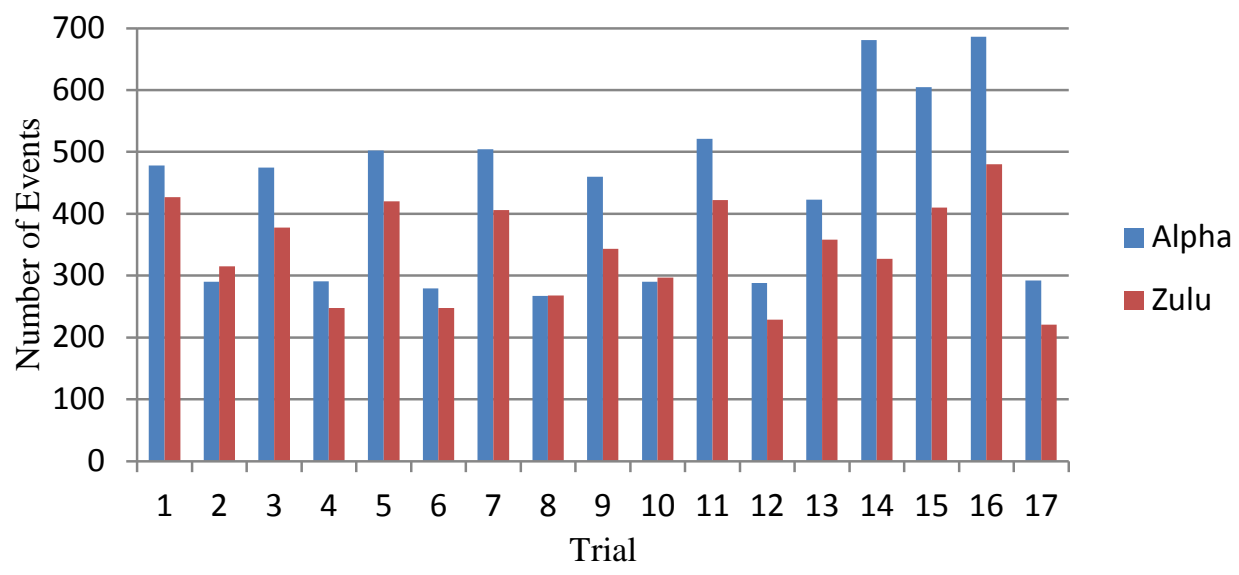

Figure 2. Number of action events in each trial. This graph indicates the increase in action events for trial 16, and that ATC Alpha on average executed more action events than ATC Zulu.

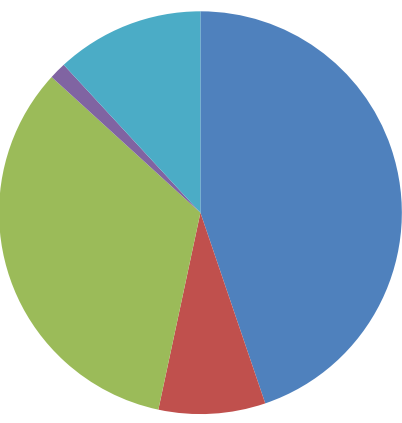

ATC Alpha during lower workload

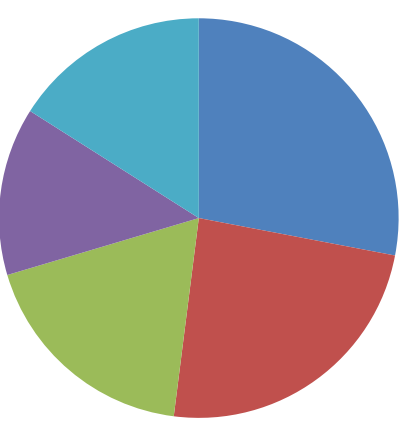

ATC Alpha during higher workload

ATC Alpha
Speed
ATC Alpha
Altitude
ATC Alpha
Descend Via
ATC Alpha
Heading
ATC Alpha
Route



ATC Zulu during lower workload

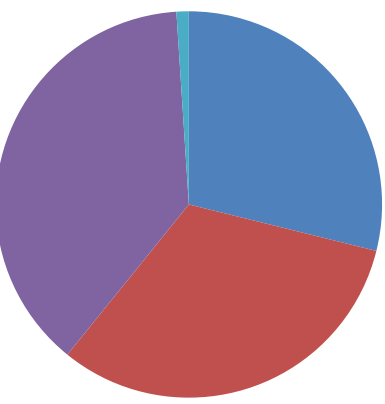

Alpha Speed

- Trial 16 ATC Alpha Altitude

Trial 16 ATC Alpha Descend Via

- Trial 16 ATC

Alpha Heading

ATC Zulu during higher workload
Trial 16 ATC

Zulu Speed

ATC Zulu
Speed
ATC Zulu
Altitude
ATC Zulu
Descend Via
ATC Zulu
Heading
ATC Zulu
Route

Trial 16 ATC

Zulu Altitude

Trial 16 ATC

Zulu Descend

Via

Trial 16 ATC

Zulu Heading

Figure 3. Controller Strategy. These pie charts indicate the difference in strategy between controllers. ATC Alpha issued many clearances of each type during high workload, whereas ATC Zulu used speed, altitude, and heading. 
When a descend via instruction is given, the aircraft will ideally descend through the airspace with little or no need for interaction with the ATCs. Similarly, the aircraft can be given instructions which include different waypoints, usually requiring them to turn off their previous route. When an ATC reads a route for the aircraft to fly, the aircraft will continue to descend to altitudes and at speeds which are congruent with the previously defined charts. For the purpose of this paper, this is regarded as being given a route clearance.

The pie charts in Fig. 3 demonstrate some of the differences in strategy between ATC's Alpha and Zulu. For many of the trials the modus operandi of ATC Alpha is to issue speeds and descend via instructions, with a limited number of altitude and route clearances. On the other hand, ATC Zulu issues many altitude clearances, followed by speeds, and finally some headings. This data indicates that both ATCs attempted to control the aircraft's time to arrive at the meter fix using speeds, but the similarities stop there. Interesting to note is how the strategies of each controller changes from most of the trials compared with the more demanding trial. ATC Zulu gives many more heading changes in exchange for the comparative number of altitude changes. ATC Alpha on the other hand decreases the number of aircraft allowed to descend on the route as normal and speed changes, and increases the number of altitude and heading clearances. In order to burn more time off aircraft expected arrival time ATC Zulu used more airspace in the form of heading changes, which can indefinitely create more delay. ATC Alpha on the other hand probably felt as if using speed to meet the expected time of arrival was not drastic enough to make the changes necessary. It is interesting that Zulu decided to decrease the relative number of altitude clearances in the higher demand situation, while Alpha decided to increase the relative number of altitude clearances, and they both increased the number of heading clearances given. They both felt something more drastic was needed to create delay, but they responded in different ways.

\section{Aircraft Off-Route}

Another piece of information collected from the experimental runs is the number of times and amount of time per trial an aircraft was off-route. Any aircraft that is instructed to fly a heading is considered off-route. This is significant because observational recordings suggest ATC Alpha gave few headings, and therefore had few off-route aircraft, because Alpha preferred more often to instruct aircraft to fly to a particular fix, and to then continue their flight as previously indicated in their flight plan. ATC Zulu on the other hand, preferred to instruct aircraft to fly on a particular heading, putting that aircraft off-route. As expected, the off-route data collected give converging validity to the assertion that these observational notes are valid, as seen in Table 1.

The off-route data presented also adds validity to the assumption that trial 16 elicits greater demand than many of the other trials. It is often quicker in the moment to instruct an aircraft to follow a heading. Then, worry about getting that aircraft back on course later, as opposed to constructing a valid route which matches requirements for meter fix arrival time and aircraft separation. Showing that both ATCs, especially Alpha, sent more aircraft on headings is evidence that there was greater time pressure managing airspace during that particular trial.

\begin{tabular}{|c|c|c|c|}
\hline & & $\begin{array}{c}\text { average \# of times off- } \\
\text { route }\end{array}$ & $\begin{array}{c}\text { average amount of time off- } \\
\text { route }\end{array}$ \\
\hline \multirow{2}{*}{$\begin{array}{c}\text { all } \\
\text { trials }\end{array}$} & ATC Alpha & .94 & 181.88 \\
\cline { 2 - 4 } & ATC Zulu & 4.53 & 677.88 \\
\hline \multirow{2}{*}{$\begin{array}{c}\text { both } \\
\text { controllers }\end{array}$} & trial 16 & 10 & 1687.50 \\
\cline { 2 - 4 } \multicolumn{2}{|c|}{ ATC Alpha trial 16 } & 2.28 & 351.28 \\
\hline \multicolumn{2}{|c|}{ ATC Zulu trial 16 } & $5^{*}$ & $1120^{*}$ \\
\hline
\end{tabular}

Table 1. Aircraft off-route. This table compares the number of times and amount of time that aircraft were off-route during the trials and between controllers. *Not an average.

\section{Closest Point of Approach}

A common method of determining safety in a simulated ATC environment is to count LOSs. In en route airspace this is typically defined by an aircraft approaching another aircraft within $1000 \mathrm{ft}$ vertically and 5mi horizontally. This measure is hard to utilize in realistic simulations however, because LOSs rarely occur. Instead, the CPA, as operationalized for this paper, is defined as an aircraft which approaches another aircraft within 1000ft vertically and 5-10mi horizontally. The assumption is that the closer together aircraft are the more difficult it will be to separate them, thus less safe. CPA also provides another way to verify that trial 16 is more difficult, on average, than the other experimental trials. Although the numbers are perhaps too close to postulate a real difference, the average number of CPA events in trial $16(M=3)$ is higher than the average number over the course of the rest of the trials $(M=1.97)$. 
The average number of CPA events, combining all trials, for ATC Alpha $(M=2.59)$ is higher than that of ATC Zulu $(M=1.47)$, with 4 CPA events for Alpha and 2 CPA events for Zulu in trial 16 . This number may be more difficult to interpret, though. There are many reasons Alpha could have a greater number of CPA events than Zulu. Perhaps, Alpha's strategy allows for better prediction of aircraft location and use of airspace, without worrying about aircraft proximity. Possibly, Alpha had a set-it and forget-it strategy, causing aircraft to occasionally come unexpectedly close to other aircraft. However, based on the plots in Fig. 1, it seems more likely that ATC Alpha was forced to use more airspace because of the employed strategy. Using airspace to absorb delay, rather than using altitude, naturally causes aircraft to come into closer proximity. Without making any declaration of unsafe circumstances regarding the strategy of ATC Alpha, it seems that the potential is there for the strategy of ATC Zulu to be safer.

\section{E. Path Distance}

The distance travelled by aircraft within controllers' airspace can help determine if differences exist between strategies, in terms of efficiency. Given identical scenarios, if the paths aircraft fly have greater distances in one case versus another, it can usually be assumed that when aircraft fly a greater distance more fuel is burned, and is more costly. Visual inspection of the plots provided in Fig. 1 might lead to the assumption that in this trial ATC Alpha controlled aircraft in a less efficient manner than ATC Zulu. However, presenting path distance numbers will help to verify this assertion.

There are a couple notes to mention regarding flight path distance for these results. First, the flight path distance reported here starts at an equidistant $200 \mathrm{mi}$ arc from the meter fix. If an aircraft started the scenario inside this arc it is not included in the analysis. Also, the numbers reported here are miles above that $200 \mathrm{mi}$ minimum required travel distance. Next, the aircraft path distance requires that the aircraft travel through both experimental sectors, not just the single airspace sector, which is the focus of this paper. Therefore, it must be taken into account that another ATC managed the aircraft through their sector. However, this data agrees with other data and conclusions presented.

As can be seen in Fig. 4, distance for the arrival aircraft travelling within the airspace in trial $16(M=14.34)$ is greater than the average number over the course of the rest of the experimental trials $(M=9.86)$. Again, this provides evidence for the assertion that trial 16 is more demanding than many of the other trials. The average distance aircraft travelled through the airspace for ATC Alpha $(M=11.22)$ is higher than that of ATC Zulu $(M=8.96)$. More specifically, and obvious in Fig. 4, the aircraft in trial 16 in ATC Alpha's airspace travelled farther $(M=16.90)$ than in ATC Zulu's airspace ( $M$ $=11.78)$, confirming the suspicion that in a higher workload environment, the strategy employed by ATC Zulu may be more efficient than the strategy employed by ATC Alpha.



Figure 4. Aircraft path distance. This graph indicates the distance above 200 miles flown on average by aircraft for each trial and controller. Trial 16 shows greater distances flown and ATC Alpha's aircraft also flew greater distances on average than ATC Zulu.

\section{F. Workload Queries}

As mentioned in the Methods section of this paper, the subjective workload of participants is collected in two formats. First, the ATCs are asked to rate their own workload on a 1-6 scale every three minutes during the course of each trial. Second, after each trial the ATCs are asked to rate their workload for the trial on several different subscales, including: mental activity, time pressure, frustration, and overall success with aircraft separation.

The real-time workload ratings over all trials show a difference between the two ATCs, such that ATC Alpha tended to give lower ratings $(M=2.70)$ than ATC Zulu $(M=3.46), F(1,632)=140.64, p<.001$. These differences 
are likely a reflection of individual differences in the way ATCs correlate their own workload with a workload rating. Given these differences between the two controllers it may not be prudent to compare the online workload ratings directly between the controllers to come to any conclusions about strategy. Instead, comparing the difference between the average rating over the trials with each ATCs rating on trial 16 might show differences in the extra burden posed by the more demanding scenario. For ATC Alpha, the difference between the average rating and the trial 16 rating is .99 , while the difference in average and trial 16 for ATC Zulu is .58. While the amount of increase for ATC Alpha is only .41 more than ATC Zulu's increase, half a rating point on a 6-point scale may actually be substantial. Combined with the posttrial workload ratings in the coming paragraphs, this may indicate that ATC Zulu had to make fewer adjustments in order to handle the increased demand from trial 16.

The real-time workload ratings verify that trial 16 was more difficult than the rest of the trials. A post-hoc

\begin{tabular}{|l|l|r|r|r|}
\hline \multicolumn{2}{|c|}{} & Mean Difference & Standard Error & Significance \\
\hline \multirow{8}{*}{ Trial 1 } & $.526^{*}$ & .165 & .002 \\
\cline { 2 - 5 } & Trial 2 & $.982^{*}$ & .168 & .000 \\
\cline { 2 - 5 } & Trial 3 & $.396^{*}$ & .166 & .018 \\
\cline { 2 - 5 } & Trial 4 & $1.130^{*}$ & .166 & .000 \\
\cline { 2 - 5 } & Trial 5 & $.618^{*}$ & .166 & .000 \\
\cline { 2 - 5 } & Trial 6 & $1.026^{*}$ & .165 & .000 \\
\cline { 2 - 5 } & Trial 7 & $.693^{*}$ & .166 & .000 \\
\cline { 2 - 5 } & Trial 8 & $1.395^{*}$ & .165 & .000 \\
\cline { 2 - 5 } & Trial 9 & $.711^{*}$ & .165 & .000 \\
\cline { 2 - 5 } & Trial 10 & $1.158^{*}$ & .165 & .000 \\
\cline { 2 - 5 } & Trial 11 & $.455^{*}$ & .166 & .006 \\
\cline { 2 - 5 } & Trial 12 & $1.079^{*}$ & .165 & .000 \\
\cline { 2 - 5 } & Trial 13 & $.868^{*}$ & .165 & .000 \\
\cline { 2 - 5 } & Trial 14 & .217 & .169 & .200 \\
\cline { 2 - 5 } & Trial 15 & $.399^{*}$ & .168 & .018 \\
\cline { 2 - 5 } & Trial 17 & $.789^{*}$ & .165 & .000 \\
\hline
\end{tabular}

Table 2. Real-time workload ratings. This table indicates a difference in workload between Trial 16 and most other trials. *Significant at .05 level.

analysis via an ANOVA, in

Table 2, shows the ratings for both ATCs in trial 16 rated significantly higher than every other trial in the experiment, $p<.05$, with the exception of trial 14 .

On average ATC Alpha reports in the post-trial questionnaires a lower level of work $(M=4.82)$, lower level of time pressure $(M=3.88)$, lower level of frustration $(M=2.12)$, and a higher level of success $(M=5.94)$ than ATC Zulu $(M=5.59,4.82,2.47,5.18$, respectively). Given the differences reported for the real-time workload queries presented earlier, we can again assume these differences are a combination of currently unverifiable factors. Something that may be of interest though is the difference in the average rating for each controller and the rating given in trial 16. Table 3 shows that the level of work, time pressure, and frustration increased more in trial 16, compared with their average rating, for ATC Alpha than for ATC Zulu. Therefore, this data might seem to indicate that, regardless of individual reporting differences, the burden on ATC Alpha increases more with an increase in difficulty, compared to ATC Zulu.

\begin{tabular}{|c|c|c|c|c|}
\hline ATC & work & time pressure & frustration & success \\
\hline Alpha & 2.18 & 2.12 & 1.88 & -1.94 \\
\hline Zulu & .41 & .18 & -.47 & -1.18 \\
\hline
\end{tabular}

Table 3. Post-trial workload ratings. This table indicates the amount of difference in the ratings given in Trial 16

\section{Discussion}

The results suggest confirmation of the two primary assumptions; that the observed strategies for the two controllers, are indeed dissimilar, and that the trial chosen for ATC comparison imposed greater demand. While not intentionally implemented into the design of the study, post hoc differences are seen in the demand required to manage traffic between this trial and many of the other experimental trials. This is likely due to the actual scenario used in the trial. The scenario for trials 14 and 16 were unfamiliar to the participants prior to run 14 .

The differences in the ability of the two ATCs to manage aircraft during the more demanding situation, with the specific set of tools and automation provided may seem to suggest that these tools and the automation get in the way of allowing the controller to proficiently manage their tasks. However, it can largely be assumed that learning to become adept with advanced concepts, tools, and automation over the course of a week does not compare with the fundamental skills learned over the course of a career. Furthermore, ATC Alpha made a concerted effort to use the tools. Alpha likely felt the urge to help researchers evaluate the new tools, concepts, and automation. ATC Zulu on the other hand was quick to lean on tried and true techniques. If a controller manages aircraft similarly in multiple 
experiments, regardless of tools, concepts, etc., then arguably that controller is going to be better able to manage sector traffic, and perform more consistently, than the controller who tries to use the different tools and concepts that accompany each experiment. This is certainly not always going to be the case, but is a consideration for the current experiment. The tool user may even become less practiced in the fundamental techniques they had traditionally used to manage airspace during their professional careers. An effort to understand these implications this might be possible, for example, by comparing conditions in which the controllers are forced to use the automation and advanced tools often, and in which they are allowed to manage aircraft using more familiar techniques and strategies.

More than just comparing the difference in strategy between the two controllers during the high demand situation, it is also useful to compare each ATCs own strategies between less and more demanding situations. How each controller handles and adapts to the increased difficulty is likely to inform our understanding of controller strategy during demanding situations as much as comparing the difference in strategy between controllers during those times. When the demand increased, even the tool using controller deferred to manual control. Under time pressure, manual control results in quicker action than using the route planning tools and taking into account the suggestions of the automation. Instead of only relying on manual control when demand increases, one suggestion is to provide controllers with just enough information, in the form of automatically generated solutions, to quickly, safely, and efficiently manage aircraft delay times manually to a meter fix when their workload is high.

The ability to switch strategies based on demand is a skill worth training, especially in the NextGen air traffic management environment. Both controllers were able to adjust techniques and strategies of control once the trial became more difficult, although with different levels of effectiveness. An emphasis should be placed in training which eliminates the reliance on any one strategy. Working knowledge of the different traffic management techniques available to them, as well as when to effectively implement them will help to avoid potentially unsafe situations, and will certainly aid efficiency.

One particular limitation of this exercise is that individual differences in the data are attributed to differences in strategy and tool use. However, individual differences caused by culture, personality, intelligence, etc. will play a big factor in the results, especially when only comparing two individuals. Therefore, future work intended to dig deeper into this subject would benefit greatly from recruiting more individuals. It is possible, however, to revisit previous experiments with the intention of comparing the strategies of individual controllers managing identical airspace.

The combination of all the information presented here helps to update understanding of automation and tool design and implementation for use in environments which exemplify not only high demand, but also user strategy changes based on dynamic events and situations. This increased understanding can also help to inform methods of training for proficiency in said environments. With the increased usage of automation and advanced tools in the air traffic management setting, either tools and the implementation of automation need to dynamically adapt to people and situations or training methods need to adapt to allow different people to use the same tool proficiently and effectively, or both.

\section{Appendix}

\section{How much mental and perceptual work was required when you were busiest during this run?}

Only answer this question if the following conditions are met:

" ((I2.NAOK == "A1" or 12.NAOK == "A2" or 12.NAOK == "A3" or I2.NAOK == "A4"))

Please choose the appropriate response for each item:

\begin{tabular}{|c|c|c|c|c|c|c|}
\hline 1 Very & & & $\begin{array}{c}4 \\
\text { Moderate }\end{array}$ & & & \\
\hline $\begin{array}{l}\text { Low } \\
\text { Mental }\end{array}$ & & & $\begin{array}{c}\text { Moderate } \\
\text { Mental }\end{array}$ & & & $\begin{array}{l}\text { High } \\
\text { Mental }\end{array}$ \\
\hline Activity & 2 & 3 & Activity & 5 & 6 & Activity \\
\hline 0 & 0 & 0 & 0 & 0 & 0 & 0 \\
\hline
\end{tabular}




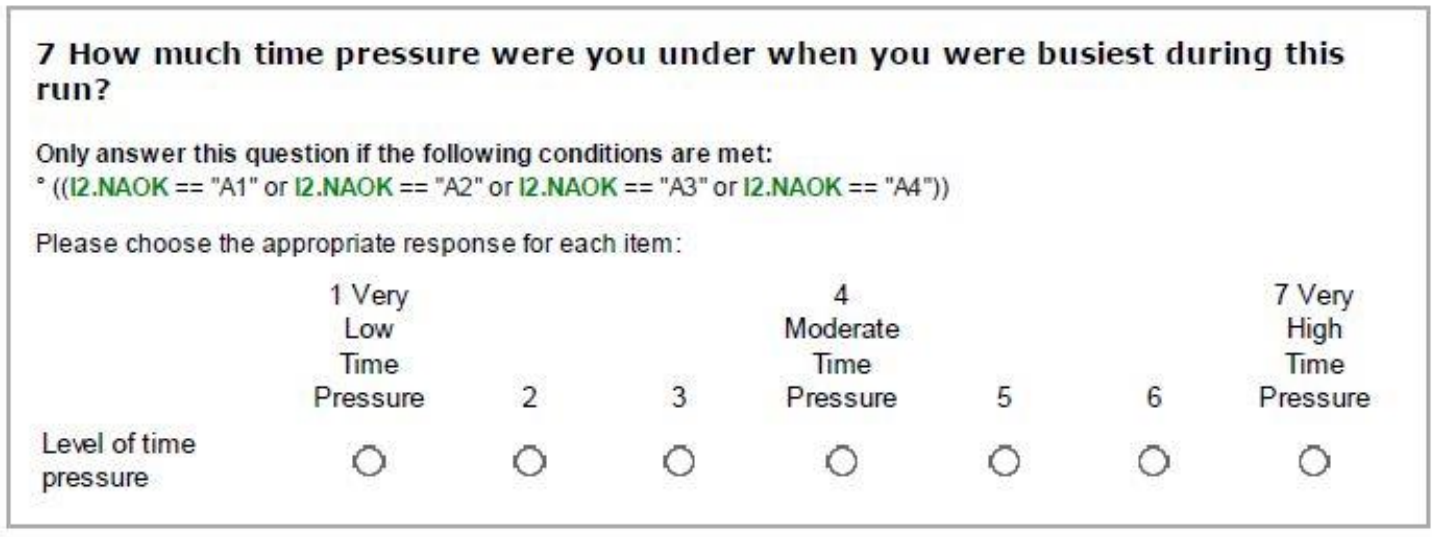

\section{How frustrated were you when you were busiest in this run?}

Only answer this question if the following conditions are met:

" $((12 . \mathrm{NAOK}==$ "A1" or $12 . \mathrm{NAOK}==$ "A2" or $12 . \mathrm{NAOK}==$ "A3" or $12 . \mathrm{NAOK}==$ "A4"))

Please choose the appropriate response for each item:

$\begin{array}{lccccccc}\begin{array}{c}1 \text { Very } \\ \text { Low } \\ \text { Frustration }\end{array} & 2 & 3 & \begin{array}{c}4 \\ \text { Moderate } \\ \text { Frustration }\end{array} & 5 & 6 & \begin{array}{c}7 \text { Very } \\ \text { High } \\ \text { Frustration }\end{array} \\ \text { frustration } & 0 & 0 & 0 & 0 & 0 & 0 & 0\end{array}$

\section{How successful do you think you were in accomplishing proper separation and delivering a good feed to your low sector?}

Only answer this question if the following conditions are met:

- ((I2.NAOK == "A2" or I2.NAOK == "A4"))

Please choose the appropriate response for each item:

\begin{tabular}{|c|c|c|c|c|c|c|c|}
\hline & $\begin{array}{l}1 \text { Not At } \\
\text { All }\end{array}$ & 2 & 3 & $\begin{array}{c}4 \\
\text { Moderately } \\
\text { Successful }\end{array}$ & 5 & 6 & $\begin{array}{c}7 \text { Very } \\
\text { Successful }\end{array}$ \\
\hline $\begin{array}{l}\text { Level of } \\
\text { success }\end{array}$ & 0 & 0 & 0 & 0 & 0 & 0 & 0 \\
\hline
\end{tabular}

\section{Acknowledgments}

This work was conducted as part of the Functional Allocation and Separation Assurance research focus area, funded by the Concept and Technology Development Project within NASA's Airspace System Program. The authors acknowledge the contributions of many individuals in the Airspace Operations Laboratory in the HumanSystems Integration Division's system support group, as well as Minghong $\mathrm{Wu}$ and Steven Green in the Aviation Systems Division.

\section{References}

${ }^{1}$ Federal Aviation Administration, "FAA's NextGen Implementation Plan 2013," URL: http://www.faa.gov/nextgen/ implementation/media/NextGen_Implementation_Plan_2013.pdf [cited 12 July 2013].

${ }^{2}$ Kirwan, B., Flynn, M., "Identification of Air Traffic Controller Conflict Resolution Strategies for the CORA (Conflict Resolution Assistant) Project," Proceedings of the 4th USA/Europe Air Traffic Management Research and Development Seminar, Santa Fe, New Mexico 2001. 
${ }^{3}$ Mogford, R. H., Guttman, J. A., Morrow, S. L., \& Kopardekar, P., "The Complexity Construct in Air Traffic Control: A Review and Synthesis of the Literature," Report to the Federal Aviation Administration, Washington D. C., CTA Inc, 1995.

${ }^{4}$ Callantine, T. J., “Air Traffic Management System Domain and Control Strategy Analysis," Proceedings of the 2004 IEEE International Conference on Systems, Man and Cybernetics, The Hague, Netherlands, 2004.

${ }^{5}$ Nunes, A., Mogford, R. H., "Identifying Controller Strategies That Support the 'Picture'," Proceedings of the Human Factors and Ergonomics Society Annual Meeting, Vol. 47, No. 71, 2003.

${ }^{6}$ Kraut, J. M., Kiken, A., Billinghurst, S., Morgan, C. A., Strybel, T. Z., Chiappe, D., Vu, K-P. L., "Effect of Data Communications Failure on Air Traffic Controller Sector Management Effectiveness, Situation Awareness, and Workload," Human Interface, Part II, HCII 2011, 6772, edited by G. Salvendy, M. J. Smith, Springer-Verlag Berlin Heidelberg, 2011, pp. 493-499.

${ }^{7}$ A. Kirlik, "Modeling Strategic Behavior in Human-Automation Interaction: Why an 'Aid' Can (and Should) Go Unused," Human Factors: The Journal of the Human Factors and Ergonomics Society, Vol. 35, 1993, pp. 221-242.

${ }^{8}$ Groce, J. L., \& Boucek, G. P., “Air Transport Crew Tasking in an ATC Data Link Environment,” SAE Technical Paper 87164, Warrendale, PA., Society of Automotive Enginners Inc., 1987.

${ }^{9}$ Talotta, N. J., Rehmann, A., Pagano, T., Zurinskas, T., Zito, F. P., Chandler, G., et al., "Operational Evaluation of Initial Data Link En Route Services,” Vol. 1, Report No. DOT/FAA/CT-90/1, I, Washington, DC: U.S. Department of Transportation, Federal Aviation Administration, 1990.

${ }^{10}$ Desmond, P., A., Hoyes, T., W., "Workload Variation, Intrinsic Risk and Utility in a Simulated Air Traffic Control Task: Evidence for Compensatory Effects," Safety Science, Vol. 22, Issues 1-3, February-April 1996, Pages 87-101.

${ }^{11}$ Morey, S., Prevot, T., Mercer, J., Cabrall, C., Martin, L., Bienert, N., Homola, J., Hunt, S., Kraut, J., M., “Controller Strategies for Automation Tool Use Under Varying Levels of Trajectory Prediction Uncertainty," Proceedings of the AIAA Aviation 2013 Conference, Los Angeles, CA (submitted for publication).

${ }^{12}$ Mercer, J., Bienert, N., Gomez, A., Hunt, S., Kraut, J., M., Martin, L., Morey, S., Green, S., M., Prevot, T., Wu, M., G., "The Impact of Trajectory Prediction Uncertainty on Air Traffic Controller Performance and Acceptability," Proceedings of the AIAA Aviation 2013 Conference, Los Angeles, CA (submitted for publication).

${ }^{13}$ Prevot, T., "Exploring the Many Perspectives of Distributed Air Traffic Management: The Multi Aircraft Control System MACS," Proceedings of the HCI-Aero, 2002, pp. 149-254. 